\title{
Like buses
}

\author{
A voyage into the unknown.
}

$\mathrm{T}$ he alien sat on the end of her bed. He wasn't very big but the bed's slender frame creaked and shifted all the same, just enough to wake Linda up. She rolled onto her back and rubbed her gungeencrusted eyes, a side effect of the recycled air. She forced them open and looked around the module - still dark but the sunrise wasn't far off. The alien reached out and placed his willowy fingers on her right ankle, gave it a little shake and said: "Hey Linda, you awake?"

"What is it, Zeek?" she asked through a yawn.

"You ever get lonely out here?"

"I told you, Zeek, we're not biologically compatible."

He chuckled. "Yeah-yeah, I know. No, I just mean, lonely, like, lonely for other people, company, companionship, love?"

"Jeez, there are plenty of people here, Zeek. Too many if we're being honest”

"Ten of yours and seven of mine is hardly 'plenty'. No, I mean like, falling in love, being in a relationship, you don't miss that? Didn't you have someone special at home?"

Linda sat up and stretched. She drew her legs up until she was hugging her knees and rubbed her eyes again. "Not really, not when I left anyway." She knew she wasn't going to get back to sleep now so she got up and pulled a hoodie on over her pyjamas.

"So you don't dream of anyone when you lie alone in that bed night after night?" Zeek asked, his eyes darting from Linda's to the small Mars One logo sewn into the lapel of her hoodie.

She filled a glass from the water extractor and sat down on the foot of the bed. Zeek looked up as she took a drink.

"There was a guy, I guess you could call it a regret that I have. You see, my life was always about studying and training and being the best at this thing or that thing. I just never seemed to find the time to find someone, y'know? But that last three months before we left Earth, we trained in this facility on the outskirts of the city

$\rightarrow$ NATURE.COM

Follow Futures: y @NatureFutures f go.nature.com/ mtoodm seem to be there, sitting at a back table drinking coffee and reading a book, like a real book, a paper book, and quite often we would catch each other's eye and smile and he always seemed just, nice, y'know, just nice and like it would be good to be in his company. And he was handsome and seemed smart and ... and I always thought that someday I'd go over and say 'hi' but, well ... here I am."

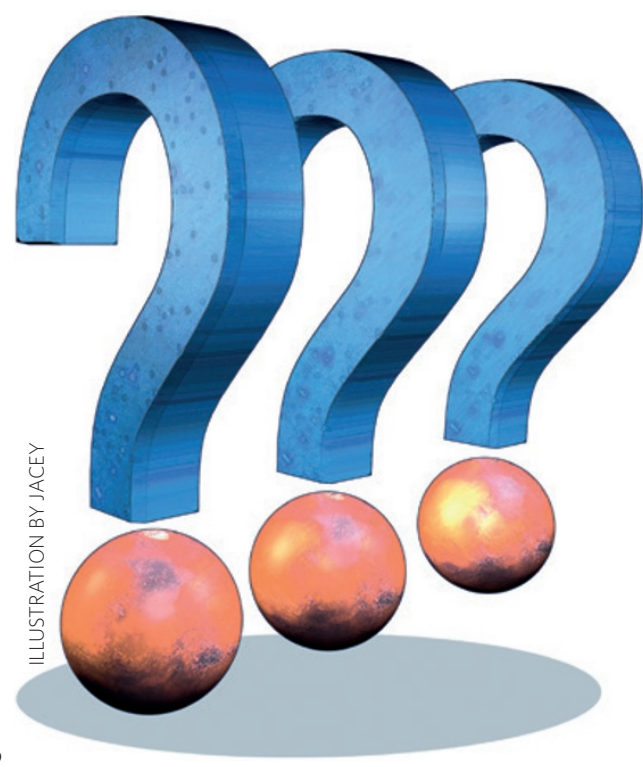

"That's a real shame, Linda."

Zeek took the glass she offered and he sipped. Cool, clean water, such a treat.

"How about you?" Linda asked.

"An idiot like me? Come on, who'd have me?"

"Idiot? You learned fluent English in three weeks. Come on, I told you about mine. Spill!"

"Ah well, you know. Our planet's a lot smaller than yours, seems so anyway. I wasn't having a good time. Messy, messy break-up. Seemed like everywhere I turned she was there and I'd get that feeling, you know that feeling you get where it's like your heart has been ripped out and set on fire and then wrapped in barbed wire and put through a mincing machine?"

"Do you guys even have hearts?"

"Funny," Zeek said. "You know we have hearts. Hey, do you want to hear mine beating?" He pointed to his left ass-cheek.
"Funny," Linda said.

She got up and walked to the window, looked out across the dusty plains to the pale mountains blushing in the distance. Not long till sunrise now. She could see the dull red glow burning behind the Nereidum range.

Zeek jumped down from the bed and scurried across to where she stood. $\mathrm{He}$ climbed up a wiring conduit and perched on the narrow windowsill.

"Lots of people said that seeing a single sun rise wouldn't be spectacular," Zeek said. "Not as glorious as our binary rises, at any rate. But I don't know. I like this just fine."

The sun peered above the mountain peaks and the module was washed in a rich red light. Zeek laughed quietly to himself.

"What's so funny," Linda asked.

"Just thinking, what are the chances that two civilizations would send spacecraft to the same small red dot in the sky at virtually the same time? And it's even more crazy when you factor in that we had to travel almost six times farther than you guys. What are the chances that we'd arrive ten days apart?"

Linda smiled and said: "Back home we've got a saying: like buses. It comes from the fact that sometimes you'll be waiting on a bus and then several show up at once." She looked over to see if he understood but Zeek wasn't listening.

"I know why both our species wanted to do this," he said "It's not a good idea to have all your breeding pairs on one rock. But why did we do this? Why did we come here when we know there's no going back?"

Linda thought about it for a time, tried to put the words in an order that would cheer her friend up, but in the end all she could say was: "Because there are questions that we don't know the answers to yet, and that's the one thing we just can't endure."

Zeek smiled through his tears. And Linda put her hand on his narrow shoulders as the sun streamed in and warmed their bones.

MARTIN HAYES'S latest book is the gutripping graphic novel Abominable Glory. Follow his ever declining mental state at www.paroneiria.com and@martinhayes. 